\title{
La nota gastronómica y el artículo de costumbres
}

\author{
Nuria BLANCO HERNÁNDEZ \\ Universidad Complutense de Madrid \\ nuriblan@gmail.com
}

Recibido: 27 de septiembre de 2014

Aceptado: 30 de enero de 2015

\begin{abstract}
Resumen
En la relación periodismo-gastronomía el artículo de costumbres merece una mención especial. Es un género cuyas características comparte denominadores comunes con el origen de unos todavía inexistentes artículos gastronómicos. Sin embargo, la afición por la descripción junto con la mención expresa de alimentos, platos, festejos y profesiones ligadas a la alimentación van a estar presentes en muchos de estos artículos, sobre todo durante los siglos XVIII y XIX. Gastronomía y alimentación encuentran así hueco en el ámbito periodístico, más allá de la receta, del que se sirve para realizar crítica social. De los mismos extraemos valiosa información sobre fondas, tipología de alimentos, consumo, elaboración de platos, higiene y tratamiento al comensal, lo que convierte a estos artículos en una avanzadilla temático-gastronómica cuya eclosión experimentamos en la actualidad.
\end{abstract}

Palabras clave: periodismo, artículo costumbres, costumbrismo, gastronomía, alimentación.

\section{Gastronomic note inside article customs}

\begin{abstract}
In the journalism-related food habits article deserves special mention. It's a genre whose characteristics shared commonalities with the origin of some culinary items still exist. However, the love of description together with the express mention of food, dishes, festivities and food-related will be present in many of these items, especially during the eighteenth and nineteenth centuries professions. Gastronomy and food are so hollow in journalism, beyond the recipe, which is used for social criticism. In the same extract valuable information about inns, type of food, consumer, food processing, hygiene and treatment diners, making these items in a thematic-culinary outpost whose emergence we experience today.
\end{abstract}

Keywords: journalism, article customs, folk literature, gastronomy, food.

\section{Referencia normalizada}

BLANCO HERNÁNDEZ, Nuria (2015): "La nota gastronómica y el artículo de costumbres". Estudios sobre el Mensaje Periodístico. Vol. 21, Núm. 2 (julio-diciembre), págs.: 953-967. Madrid, Servicio de Publicaciones de la Universidad Complutense.

Sumario: 1. Pícaros, costumbristas y románticos. De la novela picaresca al artículo de costumbres. 2. El artículo de costumbres: antecedentes, características y evolución. 3. El artículo de costumbres y la nota gastronómica. 4. Conclusiones. 5. Referencias bibliográficas.

\section{Pícaros, costumbristas y románticos. De la novela picaresca al artículo de cos- tumbres}

La definición y establecimiento del género de costumbres ligado a la literatura no está exenta de complicaciones. Su variedad temática, donde la comida aparece en forma de nota sobre alimentación, costumbres y relaciones sociales en torno a la mesa, hacen del género literario costumbrista el punto de partida gracias al cual la prensa da cabida al artículo de costumbres. En el mismo, encontramos además las huellas inconfundibles -detalles cotidianos sobre alimentos, cocinas, profesiones, objetos, individuos y sociedad- que lo relacionan con el hoy catalogado como periodismo gastronómico, donde la crónica, la crítica y el reportaje gastronómico representan mayor grado de afinidad.

Esa cotidianidad inserta en los artículos de costumbres, en la que la riqueza de detalles es la nota principal, quedó reflejada en un primer momento en la novela pica- 
resca. Tras la cual, Miguel de Cervantes y sus obras, en las que se citan múltiples referencias sobre productos y cocina manchega ${ }^{1}$, recogen el testigo literario para dar origen a la novela costumbrista. Su posterior desarrollo conducirá a la novela romántica y las páginas del periódico donde origina un género periodístico propio.

En el periódico, el artículo de costumbres retrata los pormenores de su tiempo con gracia, ironía y minuciosidad. Con la clara intención de advertir o señalar cuestiones relevantes para el país y su devenir. Sus textos narran la intrahistoria nacional que con tanta frecuencia nos define. Sin embargo, las posibilidades del costumbrismo a la hora de escribir hacen necesario diferenciar entre costumbrismo y artículo de costumbres, aspecto en el que han coincidido la mayoría de investigadores a la hora de establecer género y origen.

En una de las obras del célebre Cervantes encontramos el punto de partida del costumbrismo literario. $M^{a}$ de los Ángeles Ayala (1993) señala (no sin antes advertir que hay menciones anteriores sobre este hecho, como la de hace Francisco Blanco García en La Literatura Española en el siglo XIX de 1891) que, "desde que Marcelino Menéndez Pelayo afirmara ${ }^{2}$ que el género costumbrista se inicia a partir del relato cervantino Rinconete y Cortadillo, los manuales universitarios y estudios especializados no han dejado de hacerse eco de este juicio crítico".

Rinconete y Cortadillo es la obra común y representativa (Correa Calderón, 1964: 3) de la novela costumbrista; obra en la que sus personajes comen pimientos en la casa de la cofradía de los ladrones. He aquí una primera nota de costumbres gastroalimentarias de la época, de la que Cervantes se hará eco describiendo entre la trama de sus novelas las actividades relacionadas con la agricultura, la ganadería y la alimentación. En las mismas citará con frecuencia platos tan comunes como guisos y ollas, flores -masa frita con miel-, buñuelos, pisto elaborado prácticamente con los mismos ingredientes con los que ha llegado hasta nuestros días, o las celebradas empanadas, campesina y panadera (Gil, Matallana y Torija, 2010).

Con Cervantes y su Rinconete y Cortadillo dará los primeros pasos el costumbrismo como género literario; aunque Evaristo Correa Calderón incide en que es posible encontrar muestras de este tipo de carácter costumbrista en obras que muestran a su vez vestigios de novelas picarescas y cortesanas. Obras literarias de los siglos XV y XVI en los que autores como Alfonso Martínez de Toledo, Antonio Torquemada o Eugenio de Salazar, "presentan curiosos aspectos de la vida española de entonces", (Correa Calderón, 1964: XII); que se detectaban también en la obra titulada Guía y avisos para forasteros de Liñán y Verdugo publicada en 1620; y que también aparecían en la novela picaresca descrita por Quevedo como literatura del hambre, de entre las

1 Un buen ejemplo se encuentra recopilado en "Los alimentos manchegos en la obra de Cervantes", artículo firmado por $\mathrm{M}^{\mathrm{a}}$ Eugenia Gil Merlo, $\mathrm{M}^{\mathrm{a}}$ Cruz Matallana y Esperanza Torija. Cuaderno de Estudios Manchegos n ${ }^{\circ}$ 35, 2010.

2 Estudios de crítica literaria publicado 1908 por Marcelino Menéndez Pelayo. Citado en la obra de $\mathrm{M}^{\mathrm{a}}$ de los Ángeles Ayala, Las colecciones costumbristas 1870-1885; de ahí la posterior discusión mantenida entre los estudiosos del género sobre quién se adelantó a quién al aseverar que la obra de Cervantes Rinconete y Cortadillo fue la precursora de la literatura costumbrista. 
cuales, El Lazarillo de Tormes, de mediados del $\mathrm{XVI}^{3}$, representa la novela con la que concluir que el género costumbrista venía gestándose años atrás.

Se establece así el árbol genealógico de la literatura costumbrista, en el que la novela picaresca origina la sátira social del que parte el cuadro costumbrista. La evolución del tiempo transformará la moralidad de las obras literarias del XVII durante los siglos XVIII y XIX con la preocupación de los autores, empeñados en reflejar una realidad cuya percepción es el final de ciclo. Señalar problemas e incertidumbres propias de su tiempo será una de las principales diferencias del costumbrismo durante la primera mitad del siglo XIX.

La otra perspectiva de estudio es la que pasa por la prensa, la que habla del género que interesa aquí dado que en él se encuentra la semilla del posterior -y todavía lejanodesarrollo de la temática gastronómica con autonomía propia, en la que el avance de las publicaciones agrarias del periodo compartido contribuirá en buena medida. Será la prensa agraria la que, sin perseguir dicha finalidad, resulte determinante para señalar la importancia de las cosas del comer, en este caso de la garantía de su producción, relevancia económica y trascendencia social (Acosta, 2010b).

Resulta evidente que el costumbrismo romántico avanza con el periódico a partir del XVIII (Fuentes, 1998), donde se publican poesías y obras narrativas que bien, en formato breve o por capítulos, limitadas por la condición de espacio del periódico (Palomo, 1997), están destinadas al gran público. La nueva modalidad de escritura evoluciona como género durante el XIX cuando añade a la actividad política, acontecimientos de actualidad como parte de sus propiedades, diferenciándose así del resto de manifestaciones costumbristas.

Mariano José de Larra (1809-1837), Mesonero Romanos (1803-1882), Estébanez Calderón (1799-1867) o José Clavijo y Fajardo (1726-1806) serán algunas de las figuras o articulistas más destacados. En el terreno gastronómico la firma del Dr. Thebussem $^{4}$ aparecerá con frecuencia en la prensa bien avanzado el siglo XIX, principalmente a partir de 1876 con el género epistolar, si bien la fama del costumbrismo periodístico queda acaparada, entre otros, por los autores anteriores.

Y así lo reconocemos hoy cuando todavía nos hacemos eco de la definición que del género periodístico dejó uno de sus autores más célebres, Mesonero Romanos, para quien también la prensa periódica, es decir, el medio de difusión, determinará sus condiciones formales (Forneas, 2005:293).

\section{El artículo de costumbres: antecedentes, características y evolución}

El artículo de Mariano José de Larra titulado "El Café", publicado en El Duende Satírico del Día en 1828 (Ayala, 1993: 22), goza de consenso al ser considerado el artículo en el que confluyen, por primera vez, todos y cada uno de los atributos que debe poseer un artículo de costumbres; el cual, reflejará la personalidad e intereses o preocupaciones político-sociales del autor. El Café también avanza la presencia, cotidia-

3 El ejemplar más antiguo encontrado hasta la fecha data de 1554, según la última actualización de la enciclopedia libre Wikipedia.

4 Mariano Pardo de Figueroa más conocido por el seudónimo Dr. Thebussem, (1828-1918). 
nidad e importancia del lugar que representan estos lugares como punto de encuentro y reflejo de la sociedad. El lugar perfecto desde el cual tomar el pulso al pensamiento de la época, donde la nota gastronómica es apenas escenario.

Aunque la mayoría de críticos prefieren centrar el estudio del costumbrismo moderno en desarrollo de la prensa romántica, por ser ésta, al fin y al cabo, el vehículo de difusión de los artículos de los escritores que fijan, en definitiva, las características del género, Clifford Marvin Montgomery (Ayala, 1993: 19) señala en Early costumbrista writes in Spain 1750-1830 a Eugenio García Baragaña y su folleto sobre el toreo de a pie titulado Noche Phantástica, fechado en 1750, como la primera muestra de artículo de costumbres publicado en nuestro país. Artículo que supone cierto retraso con respecto a los precursores ingleses, Joseph Addison y Richard Steele ${ }^{5}$, quienes hacía algunos años venían publicando artículos de costumbres en The Tatler, fundado en 1709. Género o estilo de redacción que pasará del país inglés a Francia y después a España, donde Mariano José de Larra y Mesoneros Romanos serán auténticos maestros (Forneas, 2005).

El artículo de costumbres tiene especial relevancia por cuanto representa en el ámbito literario y periodístico donde origina un género propio. En el ámbito del periodismo especializado en gastronomía, especialidad estrella en la actualidad, se aplicarán con profusión parte de sus características, donde la descripción detallada de los hábitos relacionados con la alimentación se centrarán en los consumos del momento con la vocación de orientar y aconsejar al lector. Sus metas además de distar en el tiempo, dista en cuanto a objetivos: el artículo de costumbres que persigue el cambio social, convive con escritos culinarios de autores como el citado Dr. Thebussem ${ }^{6}$ y con obras como recetarios y manuales. La nota gastronómica del periodo aspira a ilustrar o aconsejar en cuestiones de alimentación, cocina y protocolo en un primer momento; años más tarde, crónica y crítica gastronómicas, géneros aventurados por Thebussem, quedarán asociados al ocio y el consumo más que a cuestiones de sociedad. Recogerán su testigo evolucionando la información sobre alimentación y cocina para instalarse con derecho propio en la opinión, donde sacarán todo el jugo al hecho gastronómico.

Este artículo de costumbres, que abarca desde finales del XVII hasta el siglo XIX, es irregular en cuanto a periodicidad y goza de total independencia estilística. Por lo general responde a una composición breve, de temática variada, que atiende a la sátira de costumbres populares. Un aquí y un ahora en la que abunda la riqueza de detalles sobre escenas, lugares, sucesos o incidentes, también el reflejo de la desidia profesional (ahí queda el Vuelva usted mañana de Mariano José de Larra que aún guarda vigencia).

En su intención moralizante esconde deseos de cambio; denuncia vicios e imperfecciones de la sociedad; son, en definitiva, artículos que sacan a luz aquellos "de-

5 Idea y autores se recogen o citan al respecto tanto en la obra Movimientos literarios y periodismo en España (Palomo, 1997), como en el artículo titulado El artículo de costumbres: crónica, crítica, literatura y periodismo (Forneas, 2005).

6 Sus escritos de cocina que adoptaron la forma espitolar quedaron recopilados en la revista La Ilustración Española y Americana entre 1876 y 1882. Estos textos están recopilado en el libro La mesa moderna. Cartas sobre el comedor y la cocina cambiadas entre el Doctor Thebussem y un cocinero de su Majestad, 1888. 
fectillos leves de ignorantes y maliciosos" (Larra, cit. por Forneas, 205: 297), mientras el lector desplegaba la sonrisa o la indignación identificando personajes. Son textos brillantes, pintorescos y humorísticos, tan peculiares por cuanta mezcolanza encierran. Una fusión que también se produce en cuanto a fondo y forma pues están a medio camino del cuento y el ensayo juntos ${ }^{7}$, de ahí su complejidad.

Quizás el cúmulo de rasgos anteriores inspiró la descripción de Camilo José Cela (Forneas, 2005: 294) al diferenciar estos escritores del resto de coetáneos, agrupándolos bajo la expresión románticos impuros, cuya huella en la historia fue la transgresión periódica al amenizar y criticar su tiempo con un género cuya influencia se ha reflejado en literatura y artículos para llegar hasta nuestros días.

El artículo de costumbres se encuentra también en la escritura de articulistas contemporáneos como los desaparecidos Camilo José Cela, Francisco Umbral, o, Manuel Vázquez Montalbán, quien además de crónica política, escribió libros sobre cocina y el buen comer, y una serie de artículos específicos para El País en agosto del año $2000^{8}$. Artículos en los que dejó impresas las sensaciones que le producían platos y comidas (al gran periodista debemos igualmente las aventuras y apetitos del mítico Carvalho).

La figura del también desaparecido periodista y escritor Xavier Domingo, con su columnismo gastronómico publicado en las principales revistas políticas de la época -Historia 16, Cambio 16 o Historia y Vida-, resulta ejemplar en el terreno gastroperiodístico, así como en su relación con el artículo de costumbres cuyas notas sobre usos, consumos y costumbres gastronómicas aparecen en sus escritos con claridad.

\section{El artículo de costumbres y la nota gastronómica}

\begin{tabular}{|c|c|c|}
\hline Siglo & Título & Autor \\
\hline XVII & El glotón que come al uso & Juan de Zabaleta \\
\hline \multirow{3}{*}{ XVIII } & $\begin{array}{l}\text { Puestos de Rosalies, Mistelas y } \\
\text { Aguardientes }\end{array}$ & \multirow{3}{*}{ Diego de Torres Villarroel } \\
\hline & Las comidas y las cenas & \\
\hline & Los cocineros & \\
\hline \multirow{12}{*}{ XIX } & El hortera & Antonio Flores \\
\hline & El choricero & Santos López Pelegrín (Abenamar) \\
\hline & El ama de llaves & Juan Eugenio Hartzenbusch $^{9}$ \\
\hline & El segador & Enrique Gil y Carrasco \\
\hline & El ventero & Duque de Rivas \\
\hline & La Posadera & Vicente de la Fuente \\
\hline & El gaitero gallego & Neira de Mosquera \\
\hline & La castañera & Bretón de los Herreros \\
\hline & La romería de San Isidro & \multirow{2}{*}{ Ramón de Mesonero Romanos } \\
\hline & La patrona de huéspedes & \\
\hline & El café & \multirow{2}{*}{ Mariano José de Larra } \\
\hline & La fonda nueva & \\
\hline
\end{tabular}

7 Idea que recogen $M^{a}$ Ángeles Ayala (1993) y María Celia Forneas Fernández (2005).

8 Titulados "La vuelta a la cazuela de España. De Port Bou a Hendaya".

9 Con quien el Dr. Thebussem mantuvo específica correspondencia. 
Los antecedentes de la inclusión de la cocina en los diarios españoles se la debemos a Mariano José de Nipho, quien además de modernizar la prensa, a partir de 1758, incluye recetas entre las páginas de su periódico Diario noticioso, curioso-erudito y comercial, público y económico (Acosta, 2010b).

Alimentos, sabores, olores, procedencias, comportamientos, utensilios, lugares, profesionales o protagonistas en la venta de viandas van a tener cabida en el periódico y en el artículo de costumbres durante los siglos XVII, XVIII y XIX. Coexistieron con literatura culinaria, con recetas y recetarios, y con la información agraria en la que se desgranan los pormenores de la actividad de la cual extraer parte de los alimentos disponibles. La razón de la prensa agraria será principalmente económica, y su desarrollo o apogeo se registrará a partir del siglo XIX; sin embargo, este tipo de prensa comienza a gestarse en el XVIII con la aparición del primer periódico especializado en agricultura, El Semanario de Agricultura y Artes dedicado a los párrocos. Con él se sentarán las bases de los modelos de publicaciones posteriores que prosperan por cuanta relevancia económica durante distintos periodos posee la temática para el país (Acosta, 2010a:13).

Muchas de las menciones gastronómicas y alimentarias registradas en el artículo de costumbres, sobre modales o sobre el desarrollo de profesiones con ella relacionadas, aparecen con rango de inferioridad con respecto al eje o motivo principal que origina el artículo, pero también los hay protagonistas. Aportaciones gastroalimentarias que permanecen ante el lector como avanzadilla, como nota colorista que ilustra al tiempo que sirve de pretexto para realizar crítica social.

La inclusión de estas referencias tendrán la doble misión de amenizar, detallarán costumbres y retratarán la vida ordinaria. Al ser analizados desde la perspectiva del sustento detectamos la alimentación disponible o ausente, los alimentos en días especiales, las características de la cocina, los rudimentos cortesanos así como las tareas ligadas a la ganadería y el campo, fuentes de riqueza en el ámbito rural.

Las relaciones relevantes o con cierta periodicidad entre artículo de costumbres y aproximaciones gastronómicas (resulta imposible considerar bajo ninguna premisa estos artículos como gastronómicos) pertenecen al siglo XVIII como veremos a continuación. Las características ya mencionadas dejan, por encima de todo, constancia de los hábitos sociales instalados en el periodo del que dan cuenta o en el que se desarrolla la acción. Y en ellos también se encuentran la comida, la bebida y el conjunto de actividades que acompañan a la alimentación.

Este uso temático se aprovecha durante el periodo para explotar al máximo el objetivo del artículo de costumbres. Mediante giros lingüísticos, metáforas y sinonimias, los alimentos se convierten en el vehículo para la crítica de la sociedad y sus estereotipos.

Esas notas gastronómicas añaden realismo, mientras el lector es conducido hacia el verdadero objetivo moralizante. Menciones a mercados, plazas y productos; explicaciones, conversaciones y profesiones en torno a los alimentos que transcurren en este tipo de escenarios y que a menudo sirven para titular el artículo -"El segador", "El ventero", "La castañera", "El choricero", etc.-.

A excepción del artículo titulado "El glotón que come al uso", publicado en el siglo XVII por Juan de Zabaleta; artículo en el que se alerta sobre los peligros del acomodo 
y la gula, son los siglos XVIII -Siglo de Oro, en letras y cocina- y XIX, donde aparecen con frecuencia menciones a alimentos, comidas, elaboraciones, productos y costumbres a la hora de consumo.

Este primer artículo de finales del XVII sirve, como servirá el resto de artículos que se analizan a continuación, para esbozar, al margen de manuales y recetarios de cocina existentes en la misma época ${ }^{10}$, la gastronomía vigente. "El glotón" de Zabaleta señala también de manera específica la importancia social de las cosas del comer, materia a la que dedica todo un artículo, adelantando así el desarrollo de una temática propia.

Los artículos seleccionados que se analizan a continuación ofrecen datos sobre los alimentos disponibles. Algunos sirven para aproximar incluso su presentación. De otros, con clara intención rastreadora, extraemos más por intuición que por explicación, la metamorfosis de la receta en la gastronomía contemporánea. De ahí su doble relevancia: por un lado histórica, por otro gastroperiodística.

En "El glotón", cuya naturaleza se debe a la gula y la pereza, se mencionan los siguientes alimentos y platos propios de su tiempo: caldillo, migajas de pan tostado, vino, congrio, besugos cocidos o empanados, salmón, torreznos fritos, pollo guisado con alcaparras, platos de sazón, pucherillos de natas, criadillas, lechoncillos tostados, frutas y "tres o cuatro salsas nuevas" de las que no hay receta ni ingrediente que ilustre. Platos que enfatizan la adicción a la comida del comilón protagonista. Al mismo el autor reprochará que "sólo sabe el tiempo que es por la comida que lleva el tiempo"; le acusará de tener "el corazón en el vientre y en el vientre sus contentos"; y le recomendará para su cura "la hambre" porque "la hambre viciosa sólo se quita con la hambre" (Correa Calderón, 1964: 210).

Entrados en el siglo XVIII, Diego de Torres Villarroel es el autor de varios de estos artículos que, agrupados en Visiones y visitas de Torres con don Francisco de Quevedo por Madrid y escritos en $1746^{11}$, no sólo mencionan o contienen componentes gastronómicos en su redacción, sino que a ellos están dedicados por entero. Es el caso de "Puestos de Rosalies, Mistelas y Aguardientes", el cual aprovecha para denunciar el creciente abuso del alcohol; su excesivo consumo ha llegado a tal punto que "se ha hecho razón de estado la borrachera". Alcoholes empleados para aliviar ciertas dolencias, "reavivar pulsos remolones" y "alentar cerebros decaídos" han pasado a ser de consumo habitual (Correa Calderón, 1964: 380-81).

En "Las comidas y las cenas" el despliegue gira en torno a los utensilios y la distribución de la mesa así como a los alimentos y bebidas (ensaladas, mostos, gran va-

${ }^{10}$ Algunos ejemplos de libros de cocina que "circulaban" durante el periodo (S. XVII): Arte de cozina, pasteleria, vizcocheria y conferueira (o conserveria en ediciones posteriores) de Fco. Martínez Motiño (1611); Libro del Arte de Cozina, de Domingo Hernández de Maceras (1607); o el Panegírico al chocolate del Capitán Castro de Torres editado por Diego Díaz de la Correra (1640).

${ }^{11}$ Los aquí mencionados, al igual que el resto de artículos señalados que han sido analizados para extraer su relación y referencias a la alimentación o la gastronomía, se han extraído de la recopilación contenida en Costumbristas españoles de Evaristo Correa Calderón. Tomo I. Introducción al estudio del costumbrismo español. Aguilar 1964. 
riedad de carnes) destinados a la voracidad de los personajes a los cuales llega a cegar el juicio. Entre otras críticas, encontramos la que realiza don Francisco, tras presenciar la cena y que sirve de comparación entre el caos del banquete y el del país: "Este es el teatro donde me has representado con más viveza la corrupción de las costumbres de tu siglo; basta el informe de este desordenado banquete para conocer el estado lamentable de las cosas. [...]". Y será de nuevo será el vino otro de los objetos de crítica en el mismo artículo; pero no se criticará cualquier consumo, sino el consumo que de él hacen las mujeres y consienten los hombres. Actitud que entre otras cosas denuncia el autor porque "provoca desenvolturas", "avienta el fuego de la lujuria", "desembaraza y hace huir la vergüenza y el recato". (Correa Calderón, 1964: 408-11).

En "Los cocineros" el autor arremete contra los mismos ("cocineros interpolados de ladrón") porque entre los maestros de cocina se refugiaban muchos rufianes que "cargados de medallas" -con pasado militar- se hacían de oro, lo que sirve al autor para denunciar "el desorden y desconcierto de este siglo" y lo que nos sirve a nosotros para atisbar el lucrativo negocio. (Correa Calderón, 1964: 412-14).

Durante el siglo posterior, los articulistas del XIX continúan mencionando la alimentación, costumbres de consumo, productos y profesiones relacionadas a los mismos en muchos de sus escritos. Evidencias como la comida y la bebida, la alimentación en su sentido más amplio, es objeto de interés y recreación para el artículo de costumbres. Suponen un aditivo con el que enriquecer y amenizar la narración, lo que ocurre en la mayoría de ellos. Sin embargo, también encontramos huellas de que el asunto gastronómico y los establecimientos de comidas son protagonistas, con lo que se anuncia, como asunto de interés para el público, el desarrollo de la temática gastronómica de forma independiente.

Así, Antonio Flores en su artículo titulado "El hortera" (Correa Calderón, 1964: 1107-16), apodo que en la Villa y Corte de Madrid se daba a los aprendices de tendero, con brillantes dobles sentidos, retrata el proceso (o deformación) que sufre un imberbe aspirante a tendero mientras adquiere formación y de paso retrata personajes, critica comportamientos y con juegos de palabras da cuenta de determinadas consecuencias político-sociales.

Entre párrafos aflora la materia que aquí interesa y sus usos y relaciones, de tal modo, que al aleccionar al joven dependiente ha de dejársele comer azúcar y chocolate "una, dos o más libras hasta que se resienta el estómago y el recién llegado aborrezca los géneros coloniales y ultramarinos". Ha de enseñársele la ciencia de la mecánica de la trastienda donde aprende a colocar la mercancía y se le muestra cómo introducir la mano en un saco lleno de legumbres rancias y secas, para sacar el único puñado de granos frescos y gordos.

Por el texto pasean alimentos como café, arroz, bacalao, té, cacao clasificado según su origen (Caracas, Guayaquil o Soconusco) y bizcochos, buñuelos y leche amerengada que rodean al protagonista y explican el transcurrir de sus días:

"[...] ocupan la tarde hasta las cinco, a cuya hora vuelven a sus respectivos almacenes, no sin entrar primero en una botillería cualquiera, para apagar la sed con un cuartillo de leche amerengada y el hambre con un puñado de bizcochos". (Correa Calderón, 1964: 1107). 
Con "El choricero", el periodista y escritor Santos López Pelegrín, quien utilizó el seudónimo Abenamar para firmar muchos de sus trabajos, se dedica con profusión al cerdo y los productos que de él obtiene el choricero, y de paso, con clara intención de denuncia y empleando para ello recursos lingüísticos tales como metáforas, algunas prosopopeyas y sinécdoques, remarcar la que considera conexión directa entre el político y el enriquecimiento personal. El autor se sirve de este animal para concluir, emparejando características entre choriceros y políticos, como a su sombra, al igual que se enriquecen aquellos que viven del cerdo, "crecen los alcaldes". No es de extrañar que la palabra chorizo nos sirva ahora, como sirviera entonces, para adjetivar este tipo de comportamientos.

Es este un artículo de costumbres ejemplar donde la sátira y la crítica se recrean al analizar los vicios de su tiempo. He aquí los párrafos más representativos que toman un elemento gastronómico como pretexto para explicar, guiar y culminar con el verdadero objetivo sociopolítico del artículo: la crítica del enriquecimiento de los políticos que explotan los recursos de la ciudadanía, representados estos en la persona de un choricero, cuya rasgo principal se basaba en exprimir económicamente al animal.

"[...] hubo en el arca de Noé un animal útil para el género humano, y que, sin duda, por su excelencia (es un excelentísimo señor), tiene más nombres que ninguno de los cuadrúpedos conocidos. Este animal útil, gruñón, suculento y grasoso, se llama cochino, cerdo, gorrino, guarro, marrano y puerco. Con esto se prueban dos cosas: la excelencia del animal y la riqueza de la lengua castellana." (Correa Calderón, 1964: 1116).

"Fue un regalo que Dios hizo a la humanidad hambrienta, que esto de tener hambre la humanidad es otra de las gracias de la creación. Estamos plagados de felicidades". (Correa Calderón, 1964: 1116).

"Desde que un cochino ve la luz pública, esto es, desde que nace, es ya un ciudadano recomendable a todo gastrónomo. Entonces no se llama cerdo ni compañía, sino lechón, y los asadores son buenos testigos, que no me dejarán mentir, de que un cochinillo, o sea, lechón, asado con su manteca correspondiente, es un bocado exquisito y alimenticio como ninguno". (Correa Calderón, 1964: 1116).

"[...] habrán observado que un cochino que se halla ya en el caso de la metamorfosis, esto es, de que le conviertan en cuerpo y alma en chorizos, morcillas, butifarras y compañía, es un ciudadano respetable". (Correa Calderón, 1964: 1116).

En "El ama de llaves", Juan Eugenio Hartzenbusch, a quien el Dr. Thebussem dedicó una extensa carta con motivo de búsqueda de la re-edición del libro de Francisco Martínez Montiño, Arte de cozina, pastelería, vizcochería y conververía, se debate entre la caricatura y la descripción, "la copia" de "estas sultanas" que manejan la economía doméstica y cuya cuarta parte del salario "la empleaba en dulces y golosinas que le estropeaban el estómago". Entre sus quehaceres, la cocina y el acopio de provisiones para estirar al máximo la despensa: "[...] que de una onza de chocolate hacía dos jícaras para la poco delicada señora, espesando el líquido con harina tostada [...]". (Correa Calderón, 1964: 1087).

Enrique Gil y Carrasco en "El segador" (Correa Calderón, 1964: 1214), se queja del éxodo. Centrado en la descripción de la situación en Galicia, "que provee -de 
gente, de mozos, políticos, criados- al resto de España", en el texto se encuentran tímidas referencias a la alimentación y la cocina. Y así, reflejo realista, cita la conca o taza de caldo o la leche mazada (líquido sobrante que se obtiene tras la elaboración de mantequilla) tan habituales a la hora de cenar en aquellas mesas humildes de los hogares gallegos.

"El ventero" del Duque de Rivas (Correa Calderón, 1964: 1258) es otro ejemplo. Aunque al igual que en "El segador", al margen de la relación del establecimiento hostelero si es que se puede catalogar así dada su forma primigenia, las menciones o descripciones sobre el ritual de alimentos y comidas es breve, pero aparecen algunas notas que se suman al propio título y que merecen ser destacadas por cuanto ilustran. Ofrece detalles tanto de la venta como del origen, carácter y vida del ventero, y de los periodos de vacas flacas en los que no abundan los alimentos que servir. El verdadero objetivo de este artículo de costumbres es el de dejar constancia de la peligrosidad de las ventas, estancadas o al estilo de las del XVII, esto es, sin modernizar. De ahí que el autor se recree al explicar al lector que no es lo mismo la venta, que el ventorrillo, o el parador "que es un progreso".

En "El ventero", escrito en 1841, encontramos referenciados los siguientes alimentos y bebidas: aguardiente de pita, huevos, bacalao, arroz, vino, pan y pimientos (Correa Calderón, 1964: 1263-64). Algún que otro chorizo y una sartén enorme puesta al fuego forman menaje y comida disponibles durante la noche protagonista en una venta cualquiera. El artículo en cuestión no puede estar más alejado de la intención de ilustrar el paladar sino que sirve para dar cuenta de los personajes, más o menos íntegros, cuando no asesinos o fuera de la ley, que las gestionan y que pasan por ellas; no obstante merece la mención por ser de nuevo un artículo de costumbres donde encontramos menciones al establecimiento donde se proporciona además de cama al viajero, comida y bebida.

El testigo de "El ventero" lo recoge Vicente de la Fuente con "La Posadera" (Correa Calderón, 1964: 1294). Es este un artículo en el cual se menciona al anterior y se ponen de manifiesto las precariedades y riesgos a los que se enfrenta el viajero cuando visita las posadas, el establecimiento habitual del periodo. Una precaria hostelería, donde Madrid, según el autor, ostenta un bochornoso primer puesto por ser en la Corte donde "están en posesión de ser tan malas como las peores de España". Sirva este texto, que puede ser considerado como temático-gastronómico, para dar cuenta de problemas cotidianos, además de los vicios de una época en la que la comida no escapaba de la picardía.

Ejemplo de ello son las transformaciones que el autor relata tales como "el gato por liebre", "el agua en vino", o, "las costillas de perro asadas cual si fueran de cordero", afirmando que son prácticas habituales de estos establecimientos.

En este artículo encontramos también la alusión directa al "gastrónomo" que en estas posadas remojaba la palabra mientras empapaba en la "pringue" mendrugos de pan. Y entre los platos y alimentos que tanto disgusto provocan, según el autor, en los huéspedes que en estas posadas recalan se mencionan, aparecen: los "huevos forrados" (pasados por agua) al precio de una peseta; las sopas cargadas de pimentón, "más coloradas que una casaca inglesa" (probablemente, sopas castellanas o sopas de ajo); 
los fitambres; el vino rancio, un habitual de estas mesas; el pan sin sal; la ensalada con aceite rancio; y una especie de engrudo a base de bellotas, harina y azúcar al que dan el nombre de chocolate.

Tampoco falta en este artículo mención a los utensilios partícipes en el ritual de la comida: los feísimos cubiertos que las posaderas ponen a disposición de la clientela, "de hierro negruzco, asquerosos al olfato y repugnantes al paladar, cosas que cada una de por sí bastarían a provocar náuseas", con lo que el lector amplía más si cabe la visión que el autor quiere transmitir con todo lujo de detalles.

En "El gaitero gallego" de Neira de Mosquera (Correa Calderón, 1964: 1297) la alusión temática es menor pero no faltan, entre el discurrir de la vida del gaitero, la comida de fonda casi siempre a escote en una casa particular. En él encontramos menciones a las castañas, tazas de vino y rosquillas benditas como bebida y alimentos comunes.

La castaña es el alimento que aparece en otro artículo que ampliará el espectro de ejemplos aquí señalados para poner de manifiesto esa relación entre gastronomía y artículo de costumbres. En este caso concreto, entre alimento y profesión ligada al mismo. Me refiero al artículo "La castañera" de Bretón de los Herreros en el que el autor describe con profusión el castaño y su fruto, en un texto cargado de intención:

"Frondoso, corpulento, prócer de bella flor, regalado fruto y apacible sombra, es el castaño uno de los árboles más beneficiosos. [...], y de los glóbulos espinosos que el árbol produce sale un alimento que codician los pavos y es la delicia de otro animal... menos grato de nombrar que de comer. A las castañas deben, en efecto, su gastronómica nombradía los ricos y suculentos jamones de Caldelas y Avilés, y también el animal implume y bípedo que llaman hombre las saborea con placer, crudas o cocidas, asadas o pilongas, acarameladas por Navidad o en potaje por Cuaresma”. (Correa Calderón, 1964: 1040).

Las referencias continúan a "una fruta inverniza", "desesperación de los golosos", "que codicia el zumo de la vid". Sin embargo, a pesar de estas descripciones, detalles que tan suculentos resultan para los que investigamos la relación entre periodismo y gastronomía, he de señalar que lo que en realidad persigue el autor tomando: 1) la profesión de castañera (de la que señala más adelante, con travesura e intención, "que semejante industria data evidentemente de tiempos más remotos... acaso de tiempos de Mari-Castaña... aunque llegó al apogeo de su gloria en el último tercio del siglo pasado"); 2) los apellidos derivados del vocablo; 3 ) destacando la proeza de Francisco Javier Castaños contra los franceses en Bailén como orgullo nacional; 4) finalmente, ayudándose no menos de la etimología de la palabra castaña en cuyo origen se encierran la castidad, el pudor y la continencia; no es ni más ni menos que reclamar la honorabilidad de otros tiempos, señalar la heroicidad pérdida o criticar la falta de ella.

Para el autor, el pueblo ha perdido calidad ("y cantidad", otra crítica directa a la fuga de jóvenes y desastres ocasionados por los conflictos) en un siglo que sin embargo lleva el adjetivo de las luces cuando debiera llamarse "de los fósforos". Arremete contra la aristocracia, decaída tanto en riqueza como en prestigio, y con lo que considera vicios de su tiempo: pereza, inmovilismo, impostura, prostitución, chismorreo. Estos son los verdaderos objetivos, no la comida, no la castaña como alimento. 
"La castañera" es un ejemplo claro de esa escritura periódica costumbrista con la que entretener e informar al ciudadano, en este caso, de los males que aquejan a su tiempo, y en el que aparecen referencias alimenticias que sirven para hilar el relato.

En "La romería de San Isidro" de Ramón de Mesonero Romanos, extraída de las Panorama Matritense, el lector transita por el Madrid antiguo, del cual se reflejan historia y bullicio habitual en un día de fiesta. Danzas improvisadas, venta ambulante de buñuelos, paseos continuos de carruajes, manolas y majos... todo en torno a la ermita del santo. Tiendas de bollos surtidas de bizcochos, dulces y golosinas; puestos de pasas, higos y garbanzos tostados; leche, roscones de pan duro, tostas y soldados de pasta-flora; pichones, pollos, chuletas... Todo "un espectáculo manducante y animado", (Correa Calderón, 1964: 708), que da cuenta de la gastronomía madrileña. Escenas matritenses representadas con motivo de la celebración en la que el autor pone atención a la descripción ambiental y el humor reinante. Es este un texto enriquecedor en el que se describen los alimentos típicos de fiesta y todo el ritual que los acompaña, un texto cuasi gastronómico. Notas menores subyacen en otro de sus artículos, "La patrona de huéspedes", donde se mencionan unas "tortillas con sendos golpes de patatas y jamón", (Correa Calderón 1964: 1023).

Sobre establecimientos encontramos en Larra varios ejemplos. "La vida de Madrid"; o, el ya mencionado artículo titulado "El café" (Correa Calderón, 1964: 899) donde el autor describe como "pidió un vaso de naranja, aunque veía a todos tomar un ponch [28] o café", remarcando así voluntad y carácter; o, "La fonda nueva" (Correa Calderón, 1964: 934) como se verá a continuación con más detalle.

En dicho artículo Mariano José de Larra recrea los pasatiempos madrileños, o mejor dicho, la falta de ellos. "La fonda nueva" es un artículo donde critica costumbres y exceso de religiosidad, donde explica que la fiesta para las clases bajas gira en torno al empleo, el nacimiento o las bodas; y describe personajes cutres que acuden o ensayan a la perfección el gorroneo a la hora de comer. Retrata así una España donde se come para vivir, no se vive para comer; donde la esperanza de una gran comida va pareja a las celebraciones anteriores mencionadas o a la caradura o mal sana creatividad de algunos individuos. Este artículo nos demuestra preocupaciones o situaciones menores con respecto a la situación política y económica del país, es cierto, pero son anécdotas que ilustran el periodo, sus gentes y sus formas. En él se reflejan opiniones y sensaciones con respecto a la "hostelería" del momento, de la cual se critican precios desmesurados en relación con el servicio y cocina ofrecidos; así, cuando Larra hace mención a la Fonda de Genieys ${ }^{12}$, dice lo siguiente:

"Linda fonda: es preciso comer de seis a siete duros para no comer mal. ¿Qué aliciente hay allí para ese precio? Las salsas son bien feas; el adorno ninguno: ni alfombra, ni un mueble elegante, ni un criado decente, ni un servicio de lujo, ni un espejo, ni una chime-

${ }^{12}$ Famosa fonda madrileña del siglo XIX. La Fonda de Genieys debe su popularidad e inclusión en la literatura gracias a que introdujo la comida francesa en la cultura popular española. Aparece también citada en los Episodios nacionales de Benito Pérez Galdós -Episodios nacionales III. De Oñate a la Granja- y en la obra de teatro El poeta y la beneficiada de Manuel Bretón de los Herreros (1857). 
nea, ni una estufa en invierno, ni agua de nieve en verano, ni..., ni burdeos, ni champaña... Porque no es burdeos el valdepeñas, por más raíz de lirio que se le eche”. (Correa Calderón, 1964: 936).

Al describir la fonda Dos Amigos, se queja igualmente de que deberán salir a la comer a la calle o a la escalera, y de que no deberán olvidarse los fósforos porque de no llevarlos no podrán verse la cara. Al ser preguntado por lo que comerán, Larra, resolutivo, procede a señalar lo que podrán comer en esa y en cualquier otra fonda, dando así cuenta de la cocina popular del momento, de los platos novedosos y la forma de servirlo todo:

“QQuiere usted que le diga yo lo que nos darán en cualquier fonda adonde vayamos? Mire usted: nos darán en primer lugar mantel y servilletas puercas, vasos puercos, platos puercos y mozos puercos; sacarán las cucharas del bolsillo, donde están con las puntas de los cigarros; nos darán luego una sopa que llaman de hierbas, y que no podría acertar a tener nombre más alusivo; estofado de vaca a la italiana, que es cosa nueva, ternera mechada, que es cosa de todos los días; vino de la fuente; aceitunas maulladas; frito de sesos y manos de carnero, hechos aquellos y estos a fuerza de pan; una polla que se dejaron otros ayer, y unos postres que nos dejaremos nosotros para mañana”. (Correa Calderón, 1964: 937).

Todos estas menciones y detalles demuestran interés de estos artículos para el estudio del periodismo gastronómico. Algunos de sus autores conviven en un periodo en el que otros escritores y periodistas como el Dr. Thebussem reflejan la alimentación en sus escritos con deliberación, aunque siguiendo objetivos distintos. Algunos de ellos, sin pretenderlo, como es el caso de Juan de Zabaleta, señala con increíble antelación el interés y consecuencias, en este caso, morales del abuso o mal uso de la alimentación, de la que describe comportamientos, costumbres y platos. Muy cerca de nuestras fronteras, recién inaugurado el nuevo siglo XIX y a través de la prensa francesa, el considerado primer periodista gastronómico, Grimod de la Reynière (17591837), da cuenta de la buena cocina a todo tipo de lectores, burgueses o no, con su Almanach Des Gourmands ou Calendrier Nutritif, antecedente directo de la futura guía gastronómica ${ }^{13}$ cuya primera edición data de 1803 .

\section{Conclusiones}

A pesar de que los artículos analizados dan cuenta por encima de todo de las problemáticas político-sociales del país en distintas épocas, en ellos se detectan títulos y menciones deliberadas en torno a la gastronomía y la alimentación.

En estos artículos, alimentación y gastronomía añaden realismo y dinamizan el texto con su nota colorista y descriptiva mientras conducen al lector hacia el objetivo moralizante que da naturaleza al género periodístico.

${ }^{13}$ La información sobre Grimod de la Reynière, al menos en España, está bastante diseminada, no obstante, así aparece en el artículo La función didáctica del periodismo gastronómico en Internet de Fernando Sánchez Gómez, p.3. 
La inclusión de alimentos y bebidas en el artículo de costumbres forma una pequeña parte de la historia en la mayoría de los artículos analizados. Sin embargo, sin ser su objeto o motivo principal, todas las menciones a la alimentación encierran una lectura indirecta que trasciende y va más allá de las funciones alimenticias que le son propias.

Juan de Zabaleta supone una mención especial por considerar materia de interés o de primer orden la alimentación de su tiempo. Si bien es cierto que su intención, siguiendo el patrón costumbrista, es señalar o denunciar la gula más que profundizar en el alimento, "El glotón que come al uso" supone el anuncio de la temática gastronómica propia (abordada de manera individual o de forma específica).

Alimentos, costumbres, festejos, fondas y platos se integran en el artículo de costumbres como parte de la experiencia vital de los personajes, lo que contribuye a retratar el entorno íntimo y social de la época.

Las ocasiones en que profesiones, productos y alimentos dan título al artículo de costumbres lo hacen, principalmente, para dejar constancia por escrito de comportamientos o explicaciones de situaciones de índole político, económico o social.

Este aspecto no contrarresta el hecho de que buena parte de estos artículos representen un hito en la historia del periodismo gastronómico español. Algunos de los títulos analizados y en particular "El ventero", "La posadera" o "La fonda nueva", remarcan la importancia de la temática dando cuenta de su situación.

De esta inclusión temático-gastronómica de fondas y casas de comidas deducimos la calidad de las mismas y sus principales defectos como la falta de higiene, peligrosidad y picardía, notas que aventuran la todavía lejana crítica gastronómica nacional.

La mención expresa de cocina -platos o recetas- y alimentos contribuyen a ampliar la cartografía gastronómica del periodo al que hacen referencia. Amplían su contexto sociocultural al tiempo que evidencian una temática cuya evolución ha derivado en una especialización periodística propia.

\section{Referencias bibliográficas}

ACOSTA, Yanet (2010a): Historia de la Información Agraria. Desde el siglo XVIII hasta la agenda 2000. Madrid, Servicio de Publicaciones del Ministerio de Medio Ambiente y Medio Rural y Marino.

ACOSTA, Yanet (2010b): El periodismo gastronómico. De las recetas de las portadas a los periódicos. Análisis del anuncio del cierre de ElBulli en los principales diarios. Congreso Prensa y Periodismo Especializado, Actas. Guadalajara. En: http://dialnet.unirioja.es/servlet/libro?codigo $=510826$ [Consulta 27-10-2014].

AYALA, María de los Ángeles (1993): Las colecciones costumbristas 1870-1885. Servicio de Publicaciones de la Universidad de Alicante.

CORREA CALDERÓN, Evaristo (1964): Costumbristas españoles. Tomo I. Introducción al estudio del costumbrismo español. Madrid, Aguilar.

FORNEAS FERNÁNDEZ, María Celia (2005): "El artículo de costumbres: crónica, crítica, literatura y periodismo". Estudios sobre el Mensaje Periodístico, vol. 11, pp. 293-308. Madrid, Servicio de Publicaciones de la Universidad Complutense. 
FUENTES, Juan Francisco, y FERNÁNDEZ SEBASTIÁN, Javier (1998): Historia del periodismo español. Prensa, política y opinión pública en la España Contemporánea. Madrid, Síntesis.

GIL MERLO, M ${ }^{\mathrm{a}}$ Eugenia; MATALLANA, M ${ }^{\mathrm{a}}$ Cruz; y, TORIJA, $\mathrm{M}^{\mathrm{a}}$ Esperanza (2010): "Los alimentos manchegos en la obra de Cervantes". Cuaderno de Estudios Manchegos $\mathrm{n}^{\mathrm{O}}$ 35. Castilla-La Mancha.

PALOMO, Ma Pilar et al. (1997): Movimientos literarios y periodismo en España. Madrid, Síntesis.

ROMERO VALIENTE, Jesús (2011): Escritos Gastronómicos del Dr. Thebussem. Salamanca, Editorial Renacimiento.

SÁNCHEZ GOMEZ, Fernando (2007): "La Columna Gastronómica de Manuel Vázquez Montalbán". Revista Electrónica de Estudios Filológicos Tonos. Universidad del País Vasco. http://www.um.es/tonosdigital/znum14/secciones/estudios -24-Gastronomia.htm [Consulta: 12 de octubre de 2014].

SÁNCHEZ GOMEZ, Fernando (2010): "La función didáctica del periodismo gastronómico en Internet”. Universidad del País Vasco. En: http://www.gabinetecomunicacionyeducacion.com/files/adjuntos/La\%20funci\%C3\%B3n $\% 20 \mathrm{did} \% \mathrm{C} 3 \% \mathrm{~A} 1 \mathrm{c}$ tica $\% 20$ del $\% 20$ Periodismo $\% 20$ Gastron $\% \mathrm{C} 3 \% \mathrm{~B} 3$ mico $\% 20$ en $\% 20$ Internet.pdf [Consulta: 21 de octubre de 2014]. 